
\title{
$\angle S$ Research Square \\ Factors Influencing Patient Disclosure of Cancer Diagnosis to the Family Dentist and Medical-dental Collaboration in Cancer Care
}

Kyunghee Lee

Tokyo Ika Shika Daigaku

Kozo Takase

Tokyo Ika Shika Daigaku

Kiyohide Fushimi ( $\nabla$ kfushimi.hci@tmd.ac.jp )

Tokyo lka Shika Daigaku https://orcid.org/0000-0002-1894-0290

\section{Research Article}

Keywords: A cross-sectional questionnaire, Oral complications, Oral care, Survivorship, Internet survey

Posted Date: August 18th, 2021

DOI: https://doi.org/10.21203/rs.3.rs-761857/v1

License: (c) (i) This work is licensed under a Creative Commons Attribution 4.0 International License.

Read Full License 


\section{Abstract}

\section{Purpose}

This study was conducted to identify factors that are associated with whether cancer patients inform their family dentists about their cancer diagnosis.

\section{Methods}

We conducted a cross-sectional questionnaire study in 500 cancer patients (gastric, colorectal, lung, breast, and prostate cancer) from September 10 to 13, 2019. The factors influencing whether cancer patients report their cancer diagnosis to their family dentist were identified by multivariate logistic regression analysis.

\section{Results}

Nearly half of the respondents (42.2\%) informed their family dentist that they had cancer. The reporting behavior of cancer patients was distinctively associated with their physician's advice (odds ratio [OR] $59.3 ; 95 \%$ confidence interval $[\mathrm{Cl}] 7.7-456.3) ; 8.6 \%$ of all respondents received physician's advice to inform their dentist about their cancer diagnosis. A good relationship with the family dentist was the most involved factor (OR 1.88; 95\% $\mathrm{Cl} 1.43-2.48$ ) for reporting behavior in the group without physician's advice, whereas positive opinion of medical-dental collaboration in cancer care had little impact on the reporting behavior.

\section{Conclusion}

The results of this study indicate the need for establishing an environment for cancer patients to receive appropriate oral care wherein physician's advice and a good relationship with the family dentist are motivators for reporting a cancer diagnosis to the dentists. It is necessary to fully inform cancer patients about the benefits of medical-dental collaboration in cancer care.

\section{Introduction}

Various acute and chronic oral complications, including oral mucositis, changes in salivary volume and viscosity, dysgeusia or ageusia, and dental diseases or jaw osteonecrosis, occur during cancer treatment [1]. Oral complications have a significant functional and psychosocial impact, including pain, dysphagia, anxiety, and depression, on the quality of life of cancer patients [1-3] and affect cancer treatment, particularly on altering the intensity or interrupting treatment [3-5]. Several studies showed the benefits of starting professional dental care before cancer treatment [6-8]. Oral care during cancer treatment constitutes essential supportive care. Collaboration between the cancer treatment team and dental professionals is essential from the pretreatment to posttreatment phase $[9,10]$, and the awareness of family dentists about the patient's impending cancer treatment can facilitate the predictive assessment and implementation of preventive measures against oral complications, including consultations for early 
interventions when oral complications occur, avoidance of undesirable dental treatment during cancer treatment, and planned dental treatment or referral to dentists specialized in oral care during cancer treatment. In 2012, oral care, through preoperative medical-dental collaboration, for cancer patients in Japan was brought under the ambit of public medical insurance as "perioperative oral care" to streamline perioperative treatment and prevent oral complications. Worldwide, between 2005 and 2015, the agestandardized incidence rates for all cancers combined increased in 174 of 195 countries or regions, whereas the age-standardized mortality rates decreased in 140 of 195 countries or regions [11]. Globally, cancer cases and survivors are increasing every year, and the need for local dental clinics to provide supportive oral care to cancer patients in collaboration with cancer treatment hospitals is estimated to increase. However, dentists are often informed only after the patient's cancer treatment has been completed. Thus, there may be factors that prevent cancer patients from reporting their medical condition. For example, dental clinics in Japan have a special layout that differs from medical clinics in that there are no private rooms; instead, there are semi-private rooms or open spaces wherein patients' personal information is conveyed. Therefore, cancer patients may find it stressful to talk about their disease in such an environment. However, little attention has been paid to the relationship between patient awareness and the structure of the dental clinic. The willingness to undergo cancer screening is associated with sociodemographic characteristics [12]; however, the relationship between reporting cancer status to family dentists and patient characteristics has not been investigated and there is insufficient research on the reporting behavior of cancer patients in dental clinics. Except at the patient interview at the initial and return visits, dentists experience difficulty in collecting reliable information about a patient's disease unless it is voluntarily self-reported. To facilitate the reporting of cancer incidence by patients to their dentists to enable the administration of appropriate oral care during cancer treatment, it is crucial to clarify the behavioral motivations of cancer patients in the dental clinic.

This study was conducted to identify factors that influence the reporting of cancer incidence by patients to their dentists.

\section{Methods}

Online surveys facilitate access to many potential respondents, especially those from hidden populations [13], and as the internet population-penetration rate in Japan was 83.5\% in 2016 [14], we conducted an online questionnaire survey from September 10 to 13,2019 to collect responses in this cross-sectional study of patients with primary cancer (gastric, colorectal, lung, breast, and prostate cancer) through an online-research company (Rakuten Insight, Inc. [15]). We included only those respondents whose family dental clinic was the same as that before they were diagnosed with cancer. This study targeted the enrolment of patients with the five commonest cancers that have a high morbidity, as reported by the Cancer Information Service of the National Cancer Center Japan [16]. The exclusion criteria were: cancer recurrence, cancer types not covered by this study, multiple cancers, and "current family dental clinic is not the dental clinic the respondents visited before the onset of cancer." The questionnaires in which all items were answered were counted as valid questionnaires. The questionnaires were accepted until there were 100 respondents for each cancer. 
The screening and study surveys were conducted by an online-research company (Rakuten Insight, Inc. [15]), who provided only anonymized data. We did not communicate directly with the respondents and did not obtain any personal identifiable information. The survey followed an opt-in method to ensure tacit consent for participation. This study was approved by the ethics committee of Tokyo Medical and Dental University in February 2019 (M2018-236).

\section{Questionnaire development}

We generated the original questionnaire used in this study based on previous reports $[17,18]$ and clinical experience. The questionnaire (available as supplementary table 1) consisted of 34 items from the following five sections: (1) attribute of responders such as the year of diagnosis of cancer and the cancer treatment [attribute section]; (2) knowledge about general and oral health [knowledge section]; (3) opinion about the handling of health information of cancer patients by medical/dental/healthcare professionals [opinion section]; (4) experience after being diagnosed with cancer [experience section]; and (5) thoughts on health and oral health [characteristic section]. We used the following response options for all items except for the attribute items Q4a (physician's advice) and Q4b- $d$ (around the seat) in this survey: 4 (strongly know/strongly agree), 3 (know slightly/agree slightly), 2 (don't know slightly/disagree slightly), and 1 (strongly don't know/strongly disagree). Response options for Q4a-c were yes, no. Response options for Q4d were private room, wall, curtain, partition, no machine, no partition, and other (free comments).

\section{Variable processing}

The dependent variable in this study was the presence or absence of reporting; therefore, respondents who answered "yes" to either of the following two questions and those who answered "no" to both questions were assigned to the "reporting group" and the "non-reporting group," respectively: Q4b: "Did you tell your family dentist that you had cancer?" and Q4c: "Did you write in the medical questionnaire at your family dental clinic that you had cancer?"

To investigate the effect of the dental clinic structure, we created "private group" and "non-private group" as a dummy variable based on whether the patient's line of sight was blocked, by using question number Q4d: "Is there anything between the treatment seats in your family dental clinic?" and patients who answered "private room, wall, curtain, or partition" and "no machine or no partition" were assigned to the private group and non-private group, respectively. Moreover, as the answer to this question included "Others (free comments)," we decided that a patient who answered "reservation for only one person" and "some private rooms" should be assigned to the private group and non-private group, respectively.

To investigate the effects of residence, we decided that "designated cities and special wards" were "urban" and "others" were "rural." A previous study [19] classified their study population into four groups based on the type of residence; however, we assigned the respondents to two groups to facilitate the analysis. In Japan, the designated city is the official term for large cities, defined by the Local Autonomy Law as a city with a population of 500,000 or more, as designated by cabinet order. However, actually, 
cities with a population of more than one million, or more than 700,000 that are expected to reach one million soon, receive this designation [20]; thus, there are 20 cities, excluding Tokyo, in Japan. There are 23 special wards in Tokyo that have a similar scope as ordinary cities [20] and, therefore, these two regions were designated as "urban" areas because of their size and nature.

Reverse item processing was performed to facilitate the interpretation of the results of questions Q3d, Q3e, Q4e, Q4j, and Q5f. For the response items using sores 4 to 1, the analysis was conducted with scores 4 or 3 considered as "know/agree" and scores 2 or 1 as "do not know/disagree."

\section{Statistical analysis}

All statistical analyses were conducted using the BellCurve for Excel version 3.20 (Social Survey Research Information Co., Ltd, Tokyo, Japan). We conducted a factor analysis on 23 items related to awareness to confirm the questionnaire's supposed substructure (principal factor method with varimax rotation). We calculated Cronbach's alpha to investigate the reliability of the extracted factors (six factors as patient awareness factors). We performed a univariate analysis of 36 variables, including the abovementioned 23 items plus sex, age, residence, the environment of the dental treatment seat, etc., to identify items related to the dependent variable of this study $(p<0.1)$. The multivariate logistic regression analysis included the variables that were identified as significant on univariate logistic analysis $(p<0.05)$.

Respondents who answered yes or no to Q4a were assigned to the group with physician's advice and the group without physician's advice, respectively, and a chi-square test was used to compare both groups for the presence or absence of reporting $(p<0.05)$. Next, we conducted multivariate logistic regression analysis $(p<0.05)$ against the group without physician's advice by using each responder's factor scores calculated for the six factors in the factor analysis as the independent variables.

\section{Results}

\section{Demographics of the respondents and response tendency}

We received a total of 500 responses from 100 patients each with primary gastric, colorectal, lung, breast, and prostate cancer. Table 1 shows the demographics of the respondents; $88.8 \%, 84.6 \%$, and $92.6 \%$ of all respondents had "surgery" included in their treatment plan at the time of cancer diagnosis, were diagnosed with cancer after 2013, and had single-department family dental clinics, respectively. Moreover, 191 (38.2\%) participants informed their family dentist that they had cancer (Q4b), 97 (19.4\%) indicated that they had cancer on the medical questionnaire in their family dental clinic (Q4c), and 211 (42.2\%) answered "yes" to either of these questions (Q4b or Q4c). Furthermore, of the $43(8.6 \%)$ respondents who had received their physician's advice (Q4a), 42 (97.7\%) respondents informed their family dentist that they had cancer (Q4b or Q4c).

\section{Table 1 Demographic characteristics of all responders}




\begin{tabular}{|c|c|c|c|c|c|c|}
\hline & Total & $\begin{array}{l}\text { gastric } \\
\text { cancer }\end{array}$ & $\begin{array}{l}\text { colorectal } \\
\text { cancer }\end{array}$ & $\begin{array}{l}\text { lung } \\
\text { cancer }\end{array}$ & $\begin{array}{l}\text { breast } \\
\text { cancer }\end{array}$ & $\begin{array}{l}\text { prostate } \\
\text { cancer }\end{array}$ \\
\hline & $(n=500)$ & $(n=100)$ & $(n=100)$ & $(n=100)$ & $(n=100)$ & $(n=100)$ \\
\hline Age (mean, SD) & $62.9 \pm 9.32$ & $65.4 \pm 8.06$ & $61 . .7 \pm 8.87$ & $64.1 \pm 7.53$ & $53.8 \pm 8.15$ & $69.3 \pm 5.79$ \\
\hline Male (\%) & 69.6 & 90.0 & 78.0 & 80.0 & 0.0 & 100.0 \\
\hline Post-2013 ${ }^{\dagger}(\%)$ & 84.6 & 86.0 & 87.0 & 93.0 & 80.0 & 77.0 \\
\hline \multicolumn{7}{|l|}{ Stage (\%) } \\
\hline 0 & 9.4 & 10.0 & 5.0 & 6.0 & 20.0 & 6.0 \\
\hline$\square$ & 39.2 & 48.0 & 17.0 & 55.0 & 44.0 & 32.0 \\
\hline ૧ & 21.4 & 19.0 & 26.0 & 13.0 & 23.0 & 26.0 \\
\hline$\square$ & 14.2 & 9.0 & 40.0 & 10.0 & 7.0 & 5.0 \\
\hline$\square$ & 4.8 & 6.0 & 4.0 & 7.0 & 0.0 & 7.0 \\
\hline don't know & 11.0 & 8.0 & 8.0 & 9.0 & 6.0 & 24.0 \\
\hline \multicolumn{7}{|l|}{$\begin{array}{l}\text { Treatment plan } \\
\text { (multiple choice区 } \\
(\%)\end{array}$} \\
\hline Surgery & 88.8 & 96.0 & 99.0 & 83.0 & 100.0 & 66.0 \\
\hline Chemical treatment & 31.2 & 11.0 & 37.0 & 27.0 & 49.0 & 32.0 \\
\hline Radiation therapy & 25.0 & 1.0 & 5.0 & 10.0 & 57.0 & 52.0 \\
\hline Immunotherapy & 5.0 & 0.0 & 1.0 & 6.0 & 6.0 & 12.0 \\
\hline Others & 3.6 & 3.0 & 1.0 & 3.0 & 7.0 & 4.0 \\
\hline Familiar person (\%) & 57.0 & 55.0 & 65.0 & 58.0 & 52.0 & 55.0 \\
\hline \multicolumn{7}{|l|}{$\begin{array}{l}\text { Treatment status } \\
(\%)\end{array}$} \\
\hline Before treatment & 1.2 & 1.0 & 0.0 & 1.0 & 0.0 & 4.0 \\
\hline Among treatment & 24.6 & 19.0 & 11.0 & 20.0 & 51.0 & 22.0 \\
\hline After treatment & 73.4 & 79.0 & 87.0 & 78.0 & 49.0 & 74.0 \\
\hline Don't know & 0.8 & 1.0 & 2.0 & 1.0 & 0.0 & 0.0 \\
\hline $\begin{array}{l}\text { Dental clinic type is } \\
\text { "Single department } \\
\text { clinic style".(\%) }\end{array}$ & 92.6 & 93.0 & 95.0 & 93.0 & 90.0 & 92.0 \\
\hline Family dentist (\%) & & & & & & \\
\hline
\end{tabular}




\begin{tabular}{|lllllll|}
\hline male & 88.4 & 93.0 & 89.0 & 91.0 & 79.0 & 90.0 \\
\hline female & 7.6 & 5.0 & 8.0 & 6.0 & 13.0 & 6.0 \\
\hline other & 4.0 & 2.0 & 3.0 & 3.0 & 8.0 & 4.0 \\
\hline Private group (\%) & 62.6 & 57.0 & 67.0 & 62.0 & 72.0 & 55.0 \\
\hline † "Post-2013" is the responders who diagnosed cancer after 2013. & \\
\hline $\begin{array}{l}\text { From: Factors influencing patient disclosure of cancer diagnosis to the family dentist and medical- } \\
\text { dental collaboration in cancer care }\end{array}$
\end{tabular}

\section{Substructure and reliability of the questionnaire's consciousness items}

We conducted a factor analysis (principal factor method with varimax rotation) of the 23 items related to awareness in the questionnaire items (Table 2); six patient awareness factors were extracted as the substructure, whereas all 23 items were selected with an eigenvalue of 1 or higher. The first, second, third, fourth, fifth, and sixth factors were complications experienced, health knowledge, positive health attitude, positive opinion of medical-dental collaborative cancer treatment, opinion about the relationship between the body and mouth, and good relationship with the family dentist, respectively. The Cronbach's a-coefficient was $0.828,0.707,0.671,0.767,0.739$, and 0.589 for the abovementioned first, second, third, fourth, fifth, and sixth factors, respectively. The Cronbach's a-coefficient for all items was 0.759 .

\section{Factors associated with informing a family dentist about having cancer}

To identify factors that influenced whether cancer patients informed their family dentist (or dental clinic) about having cancer, we conducted univariate analysis that included 36 items, comprising the abovementioned 23 items plus sex, age, residence, the environment of the dental treatment seat, etc. ( $p<$ 0.1 ; available as supplementary table 2$)$, and found a significant difference $(p<0.1)$ in regard to 25 items. The private group did not differ between the reporting and non-reporting groups $(p=0.51)$, although concern (including "agree slightly") differed significantly between the reporting and non-reporting groups with regard to the presence of other patients around the treatment seat $(p=0.095 ; \mathrm{Q} 4 \mathrm{e})$. There was a significant difference between the reporting and the non-reporting group in the feeling that there was no privacy at the treatment seat (including "agree slightly"; $p=0.014 ; \mathrm{Q} 4 \mathrm{f}$ ).

\section{Table 2 Results of factor analysis for question items}


Items

Factor

$\begin{array}{llllll}1 & 2 & 3 & 4 & 5 & 6\end{array}$

(1) First factor: Complications experience $\llbracket \mathbb{a}[0.828$, Contribution ratio; $9.81 \%$ )

\begin{tabular}{llllllll} 
4g & Complications (pain, etc.) & 0.821 & 0.020 & 0.077 & 0.044 & -0.085 & -0.127 \\
\hline $4 \mathrm{~h}$ & Complications (dry mouth) & 0.841 & 0.051 & 0.100 & 0.023 & -0.147 & -0.099 \\
\hline $4 \mathrm{i}$ & Complications (taste disorder) & 0.657 & 0.139 & 0.004 & 0.049 & -0.001 & -0.025
\end{tabular}

(2) Second factor: Health knowledge( $a \rrbracket 0.707$, Contribution Rate; $8.90 \%$ )

2a Knowledge of healthy life expectancy $\quad \begin{array}{llllll}-0.252 & 0.282 & 0.126 & 0.223 & -0.042 & -0.100\end{array}$

2b Knowledge of 8020 promotion $\quad \begin{array}{llllll}-0.239 & 0.358 & 0.078 & 0.105 & -0.100 & -0.034\end{array}$

2c $\quad$ Knowledge of Medical and Dental $\quad \begin{array}{llllll}0.134 & 0.629 & 0.114 & 0.115 & -0.028 & 0.094\end{array}$ Care Cooperation

$\begin{array}{llllllll}2 \mathrm{~d} & \text { Keeping oral hygiene } & 0.073 & 0.780 & 0.080 & 0.111 & 0.205 & 0.138\end{array}$

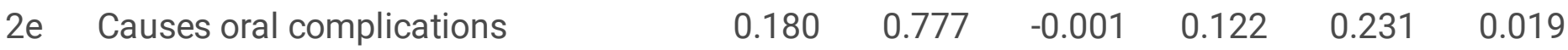

(3) Third factor: Positive attitude toward maintaining health $\square$ a 0.671 , Contribution Rate; $8.84 \% \square$

\begin{tabular}{llllllll} 
5a & Regular check-up & -0.205 & 0.141 & 0.446 & 0.161 & 0.107 & 0.078 \\
\hline $5 \mathrm{c}$ & Relationship between treatments & 0.150 & 0.037 & 0.656 & 0.320 & 0.147 & -0.118 \\
\hline 5d & Dentist opinion & 0.201 & 0.044 & 0.717 & 0.293 & 0.158 & 0.021 \\
\hline g & Conscious of life & 0.074 & 0.127 & 0.321 & 0.117 & 0.047 & -0.216
\end{tabular}

(4) Fourth factor: Positive opinion of cancer medical-dental collaboration[a $\amalg 0.767$, Contribution Rate; 7.58\% [
3a Cooperate between doctors
0.025
0.274
0.256
0.725
$0.214-0.050$
3b Automatically health data system
0.020
0.134
0.260
0.726
0.159
0.037
3c Tell the dentist
0.031
0.127
0.198
0.485
0.163
0.091

(5) Fifth factor: Opinion about the relationship between body and mouth $\square$ a 0.739 , Contribution Rate; $5.90 \%$ 口

$\begin{array}{llllllll}3 d & \text { Need to know } & -0.072 & 0.001 & 0.171 & 0.195 & 0.608 & 0.096 \\ 3 e & \text { Direct relationship } & -0.046 & 0.155 & 0.199 & 0.209 & 0.747 & -0.003\end{array}$

(6) Sixth factor: Good relationship with family dental clinic $\square$ a 0.589 , Contribution Rate; $5.80 \% \square$

\begin{tabular}{|llcccccc|}
\hline e & Other patients & -0.140 & -0.098 & -0.248 & -0.101 & 0.061 & 0.518 \\
\hline $4 f$ & Privacy & 0.102 & 0.073 & 0.037 & 0.026 & -0.048 & 0.479 \\
\hline $\mathrm{j}$ & Interest of dentist & -0.188 & 0.083 & 0.043 & 0.054 & 0.267 & 0.288
\end{tabular}




\begin{tabular}{|c|c|c|c|c|c|c|c|}
\hline $5 b$ & Satisfaction & -0.251 & 0.051 & 0.438 & -0.022 & 0.043 & 0.500 \\
\hline $5 e$ & Dentist care & 0.008 & 0.054 & 0.474 & 0.132 & 0.088 & 0.485 \\
\hline $5 f$ & Asks from dentist & -0.141 & 0.101 & -0.082 & 0.083 & 0.217 & 0.336 \\
\hline \multicolumn{8}{|c|}{ All Items; $a=0.759$} \\
\hline \multicolumn{8}{|c|}{ Cumulative contribution ratio; $46.83 \%$} \\
\hline \multicolumn{8}{|c|}{$\begin{array}{l}\text { From: Factors influencing patient disclosure of cancer diagnosis to the family dentist and medical- } \\
\text { dental collaboration in cancer care }\end{array}$} \\
\hline
\end{tabular}

To avoid overfitting, we selected 20 of the 25 items selected by univariate analysis as being relevant to the purpose of this study and calculated their correlation coefficients, but found no strong correlation ($0.25<\mathrm{r}<0.77)$. The abovementioned 20 items were included as independent variables in the multiple logistic regression analysis ( $p<0.05$; Table 3 ), and significant differences were found in four items. "Physician advice" (Q4a) had an odds ratio (OR) of 59.3 (95\% confidence interval [Cl] 7.7-456.3, $p<$ $0.001)$ and "asks from dentist"(Q5f) had an OR of 2.04 (95\% Cl 1.50-2.77, $p<0.001)$.

Table 3 Results of multivariate logistic regression analysis in all respondents $(n=500)$ 


\begin{tabular}{|c|c|c|c|c|}
\hline \multicolumn{2}{|c|}{ Items } & $\begin{array}{l}\text { Partial regression } \\
\text { coefficient }\end{array}$ & OR $(95 \% \mathrm{Cl})$ & $\mathrm{p}$ \\
\hline \multicolumn{2}{|c|}{ Male } & -0.43 & $0.65(0.40-1.07)$ & 0.09 \\
\hline \multicolumn{2}{|c|}{ Post-2013 } & 0.41 & $1.51(0.80-2.82)$ & 0.20 \\
\hline & Keeping oral hygiene & 0.11 & $1.12(0.82-1.52)$ & 0.49 \\
\hline $2 e$ & Causes oral complications & 0.09 & $1.09(0.80-1.48)$ & 0.58 \\
\hline $3 a$ & Cooperate between doctors & -0.19 & $0.83(0.52-1.32)$ & 0.43 \\
\hline $3 c$ & Tell the dentist & 0.67 & $1.95(1.32-2.87)$ & $P<0.001^{* *}$ \\
\hline $3 e$ & Direct relationship & 0.04 & $1.04(0.74-1.46)$ & 0.82 \\
\hline $4 a$ & Physician advice & 4.08 & $\begin{array}{l}59.33(7.71- \\
456.34)\end{array}$ & $P<0.001^{* *}$ \\
\hline $4 e$ & Other patients & 0.31 & $1.37(0.98-1.92)$ & 0.07 \\
\hline $4 f$ & Privacy & -0.14 & $0.87(0.63-1.19)$ & 0.38 \\
\hline & Complications (pain, etc.) & 0.30 & $1.35(0.82-2.23)$ & 0.24 \\
\hline $4 \mathrm{~h}$ & Complications (dry mouth) & 0.19 & $1.21(0.70-2.12)$ & 0.50 \\
\hline $4 \mathrm{i}$ & Complications (taste disorder) & 0.26 & $1.30(0.95-1.78)$ & 0.10 \\
\hline $5 a$ & Regular check-up & 0.32 & $1.38(0.87-2.20)$ & 0.17 \\
\hline $5 b$ & Satisfaction & 0.16 & $1.18(0.73-1.90)$ & 0.51 \\
\hline $5 c$ & $\begin{array}{l}\text { Relationship between } \\
\text { treatments }\end{array}$ & -0.33 & $0.72(0.45-1.16)$ & 0.18 \\
\hline $5 d$ & Dentist opinion & 0.15 & $1.16(0.71-1.91)$ & 0.55 \\
\hline $5 e$ & Dentist care & 0.53 & $1.69(1.13-2.54)$ & $0.011^{*}$ \\
\hline $5 f$ & Asks from dentist & 0.71 & $2.04(1.50-2.77)$ & $P<0.001^{* \star}$ \\
\hline & Conscious of life & 0.23 & $1.26(0.94-1.69)$ & 0.12 \\
\hline \multicolumn{5}{|c|}{$\star \otimes P<<0.05 * * \otimes P<<0.01$} \\
\hline \multicolumn{5}{|c|}{ Nagelkerke R2; 0.39} \\
\hline \multicolumn{5}{|c|}{ The percentage of correct classifications; $75.0 \%$} \\
\hline \multicolumn{5}{|c|}{$\begin{array}{l}\text { From: Factors influencing patient disclosure of cancer diagnosis to the family dentist and medical- } \\
\text { dental collaboration in cancer care }\end{array}$} \\
\hline
\end{tabular}


Factors associated with informing a family dentist about having cancer in the subgroup of participants without physician's advice

A chi-square test comparing the groups with physician's advice $(n=43)$ and without physician's advice ( $n$ $=457)$ showed a higher frequency of informing the dentist about having cancer (42/43) in the group with physician's advice than in the group without physician's advice $(p<0.001)$.

To identify factors related to the reporting behavior of respondents who did not receive advice from their physicians, we conducted a multivariate logistic regression analysis to focus on the group without physician's advice $(p<0.05)$. To reduce the number of variables in this multivariate logistic regression analysis, we used the six patient-awareness factors that were extracted as independent variables from the factor analysis. The correlation coefficient between each factor was $|r| \leq 0.164$. Table 4 shows the results of multivariate logistic regression analysis for the subgroup without physician's advice, and there were significant associations $(p<0.05)$ for five factors, but not for the fourth factor (positive opinion of medical-dental collaboration for cancer treatment). Factor 6 (good relationship with the family dentist) had an OR of 1.88 (95\% Cl 1.43-2.48; $p<0.001)$, and Factor 4 had an OR of 1.25 (95\% Cl 0.97-1.62; $p=$ $0.081)$.

Table 4 Results of multivariate logistic regression analysis in a "group without physician's advice"(n=457)

\begin{tabular}{|c|c|c|c|c|}
\hline \multicolumn{2}{|l|}{ Items } & \multirow{2}{*}{$\begin{array}{l}\text { Partial regression } \\
\text { coefficient } \\
0.38\end{array}$} & \multirow{2}{*}{$\begin{array}{l}\text { OR }(95 \% \\
\mathrm{Cl}) \\
1.46(1.16- \\
1.83)\end{array}$} & \multirow{2}{*}{$\begin{array}{l}\mathrm{p} \\
0.001^{* *}\end{array}$} \\
\hline Factor1 & Complications experience & & & \\
\hline Factor2 & Health knowledge & 0.35 & $\begin{array}{l}1.42(1.12- \\
1.78)\end{array}$ & $0.003^{* *}$ \\
\hline Factor3 & $\begin{array}{l}\text { Positive attitude toward maintaining } \\
\text { health }\end{array}$ & 0.28 & $\begin{array}{l}1.32(1.03- \\
1.70)\end{array}$ & $0.029^{*}$ \\
\hline Factor4 & $\begin{array}{l}\text { Positive opinion of cancer medical- } \\
\text { dental collaboration }\end{array}$ & 0.23 & $\begin{array}{l}1.25(0.97- \\
1.62)\end{array}$ & 0.081 \\
\hline Factor5 & $\begin{array}{l}\text { Opinion about the relationship between } \\
\text { body and mouth }\end{array}$ & 0.36 & $\begin{array}{l}1.44(1.11- \\
1.87)\end{array}$ & $0.007^{* *}$ \\
\hline Factor6 & $\begin{array}{l}\text { Good relationship with family dental } \\
\text { clinic }\end{array}$ & 0.63 & $\begin{array}{l}1.88(1.43- \\
2.48)\end{array}$ & $P<0.001^{* *}$ \\
\hline \multicolumn{5}{|c|}{$\star \otimes P<0.05 * * \llbracket P<0.01$} \\
\hline \multicolumn{5}{|c|}{ Nagelkerke R2; 0.17} \\
\hline \multicolumn{5}{|c|}{ The percentage of correct classifications; $68.7 \%$} \\
\hline
\end{tabular}




\section{Discussion}

Dental management that is initiated before cancer treatment is important to reduce oral complications, support patients' quality of life, and facilitate cancer treatment [6-10]. This study identified factors that influence whether cancer patients who had a family dentist before being diagnosed with cancer informed their family dentist that they had cancer. The main finding was that physician's advice was significantly related to the reporting behavior of cancer patients, and a good relationship with the family dentist was significantly associated with the reporting behavior in the group that did not receive physician's advice. To the best of our knowledge, this is the first study to investigate whether cancer patients informed their family dentist that they had cancer.

\section{Demographics of the respondents}

We obtained data from the population in high need of perioperative oral care as $88.8 \%$ of the respondents reported that surgery was included in their treatment plan at the time of cancer diagnosis; $84.6 \%$ of the respondents were diagnosed with cancer in 2013, a year after perioperative oral care was covered under public medical insurance. As $92.6 \%$ of respondents answered "single-department clinic," we considered that the data were obtained from the patient population that was treated at a general family dental clinic in Japan. According to the Japanese government-reported statistics [21], approximately $80 \%$ of dental clinics are private practices; family dentistry in Japan often means a single-department private clinic.

This survey showed that $42.2 \%$ of respondents informed their family dentist that they had cancer, and 43 respondents were advised by their physician to do so; among them, $42(97.7 \%)$ informed their family dentist about having cancer. The results of the test for the attending physician's advice and the frequency of reporting showed that the group with physician's advice differed from the group without physician's advice. Therefore, this analysis evaluated all respondents and, specifically, the group without physician's advice.

The six patient awareness factors identified by the factor analysis were as expected in the substructure of the questionnaire items. The reliability test showed that, despite the relatively low Cronbach's a for Factor 6, the Cronbach's a for the other factors were generally high and was adequate for all items.

\section{Factors associated with informing a family dentist about having cancer}

The results of multivariate logistic regression analysis for all respondents showed that physician's advice (Q4a) was distinctively associated with the reporting behavior of cancer patients in the dental clinic. Logistic regression analysis showed that inquiries from dentist (Q5f) was associated with the reporting behavior, although physician's advice was distinctively associated with informing the dentist. This result 
supports the findings of previous studies $[12,22]$ that physician's recommendations motivate asymptomatic patients and are associated with willingness to undergo cancer screening [12], and we found that physician's recommendations are a strong motivator for patient behavior. Cancer patients are less aware of their oral health due to fear of death and anxiety about treatment [23]; therefore, the attending physician needs to understand oral complications well [1] and recommend visits to a dental clinic and reporting of cancer status to a dentist to prevent and manage oral complications. Only $8.6 \%$ of our respondents were advised by their physician, and this indicates the need to encourage attending physicians to advise their patients. However, burnout is a severe problem for physicians [24-26], and the burden on attending physicians should be considered. All professions involved in cancer treatment should cooperate to ensure oral healthcare for cancer patients through a team approach $[9,10,27]$.

The results of the subgroup analysis of the group without physician's advice showed that a good relationship with the family dentist was significantly associated with reporting behavior (Table 4). Previous studies $[17,28]$ have reported that the physicians' communication style can alleviate patients' anxiety and improve satisfaction. We showed that the results of these previous studies apply to dentists and that good communication encourages the patients' reporting behavior. The complications experienced, health awareness, positive health attitude, and positive opinion of medical-dental collaboration in cancer treatment, which were significant factors (Table 4) reflect the personal experiences, knowledge, opinions, and characteristics of patients, and it is difficult for the family dentist to be directly involved. However, the OR of a good relationship with the family dentist was higher than those of the abovementioned four factors, and suggests that establishing good communication may significantly influence reporting behavior beyond the patients' personal experiences, knowledge, opinions, and characteristics. Therefore, family dentists need to regularly establish good communication with their patients.

Contrary to our prediction, positive opinion of medical-dental collaboration in cancer treatment was unrelated to reporting behavior, and may be explained by the possibility that the depth of understanding of oral care benefits during cancer treatment may be related to reporting behavior. As the second factor, health knowledge, showed significance for reporting behavior in the multivariate logistic regression analysis (Table 4), and the questionnaire items comprising the second factor included questions about the depth of knowledge of oral care: "you know the meaning of medical-dental collaboration for cancer care (Q2c)," "you know that it is important to maintain oral hygiene before and after cancer surgery (Q2d)," and "you know that cancer treatments can cause oral complications (stomatitis, taste disorders, etc.) (Q2e). Thus, understanding and recognizing the importance of oral care during cancer treatment is a behavioral motivator; however, simple awareness of medical-dental collaboration has little impact on reporting behavior. Oral care during cancer treatment reduces oral complications [6-8] and postoperative pneumonia [29] and contributes to improved quality of life of cancer patients and reduced healthcare costs [9]. In Japan, perioperative oral care, which was covered by public medical insurance since 2012, significantly prevented postoperative pneumonia [30,31] and shortened postoperative hospital stay [32]. We identified the need to fully inform patients of the significance of oral care and the benefits of medical-dental collaboration and connected them to patients' actions. 
Univariate analysis of all respondents showed that the dental treatment seat was unrelated to the reporting behavior, contrary to our prediction. However, the patient's concern about the presence of other patients around the dental treatment seat and the patient's feeling that their privacy was not protected in the dental treatment seat was related to the reporting behavior. Therefore, it is necessary to protect the patients' privacy regardless of the dental clinic's structure to enable patients to talk about their medical conditions without stress; dental professionals must focus on protecting privacy in the dental clinic and clearly indicate this to patients.

\section{Limitations}

This study's cross-sectional design precludes the detection of a causal relationship, and the change in awareness of health and oral care that occurred after reporting to the family dentist may have influenced the responses. To exclude this effect, it is desirable to evaluate the motivation for reporting behavior and the change in awareness by comparing the changes in awareness from before to after reporting in the unreported population. The results of this study do not facilitate a discussion of exclusion criteria or examination of factors other than those specified in the questionnaire. This study does not reflect differences in the distribution of cancers because the survey was conducted with 100 respondents for each cancer to facilitate analysis.

\section{Conclusion}

This cross-sectional questionnaire survey was conducted to identify factors associated with whether cancer patients report their cancer diagnosis to their dentists. Physician's advice was a strong motivator. In the group that did not receive physician's advice, the good communication of the family dentist with patients was significantly associated with reporting behavior. In order for cancer patients to inform their dentists of their cancer and receive appropriate oral care, it is necessary to fully inform cancer patients of the benefits of medical-dental collaboration in cancer care.

\section{Declarations}

\section{Funding}

This work was supported in part by Foundation for Promotion of Cancer Research in Japan.

\section{Conflicts of interest}

The authors have no relevant financial or non-financial interests to disclose.

\section{Availability of data and material}

The data used to support the findings of this study are available from the corresponding author upon reasonable request. 


\section{Code availability}

Not applicable

\section{Authors' contributions}

All authors contributed to the study concept and design. KL participated in collecting the data, analysis, and interpretation of the data. $\mathrm{KL}$ wrote the first draft of the manuscript, and all authors commented on previous versions of the manuscript. All authors contributed to the manuscript and approved the final version for submission.

\section{Research involving Human Participants and/or Animals}

This study was approved by the appropriate institutional research ethics committee of Tokyo Medical and Dental University in February 2019 (M2018-236). The authors certify that the study was performed in accordance with the ethical standards as laid down in the 1964 Declaration of Helsinki and its later amendments or comparable ethical standards.

\section{Consent to participate}

All responders participated by an opt-in method through an online research company.

\section{Consent for publication}

All respondents agreed to publish by an opt-in method through an online research company.

\section{Acknowledgement}

We would like thank all respondents who participated in this study.

\section{References}

1. Epstein JB, Thariat J, Bensadoun RJ, Barasch A, Murphy BA, Kolnick L, Popplewell L, Maghami E. (2012) Oral complications of cancer and cancer therapy: from cancer treatment to survivorship. CA Cancer J Clin. 2012 Nov-Dec;62(6):400-22. https://doi.org/10.3322/caac.21157. Epub 2012 Sep 12.

2. Kim JW, Cha Y, Kim SJ, Han SW, Oh DY, Lee SH, Kim DW, Im SA, Kim TY, Heo DS, Bang YJ. (2012) Association of oral mucositis with quality of life and symptom clusters in patients with solid tumors receiving chemotherapy.Support Care Cancer. 2012 Feb;20(2):395-403. https://doi.org/10.1007/s00520-011-1126-8. Epub 2011 Mar 11.

3. Barkokebas A, Silva IH, de Andrade SC, Carvalho AA, Gueiros LA, Paiva SM, Leão JC. (2015) Impact of oral mucositis on oral-health-related quality of life of patients diagnosed with cancer. J Oral Pathol Med. 2015 Oct;44(9):746-51. https://doi.org/10.1111/jop.12282. Epub 2014 Oct 25. 
4. Scully C, Epstein J, Sonis S. (2004) Oral mucositis: a challenging complication of radiotherapy, chemotherapy, and radiochemotherapy. Part 2: diagnosis and management of mucositis. Head Neck. 2004 Jan;26(1):77-84. https://doi.org/10.1002/hed.10326.

5. Barker GJ, Epstein JB, Williams KB, Gorsky M, Raber-Durlacher JE. (2005) Current practice and knowledge of oral care for cancer patients: a survey of supportive health care providers. Support Care Cancer. 2005 Jan;13(1):32-41. https://doi.org/10.1007/s00520-004-0691-5. Epub 2004 Nov 12.

6. Saito H, Watanabe Y, Sato K, Ikawa H, Yoshida Y, Katakura A, Takayama S, Sato M. (2014) Effects of professional oral health care on reducing the risk of chemotherapy-induced oral mucositis. Support Care Cancer. 2014 Nov;22(11):2935-40. https://doi.org/10.1007/s00520-014-2282-4. Epub 2014 May 23.

7. Schiødt M, Hermund NU. (2002) Management of oral disease prior to radiation therapy. Support Care Cancer. 2002 Jan;10(1):40-3. https://doi.org/10.1007/s005200100284.

8. Gürgan CA, Özcan M, Karakuş Ö, Zincircioğlu G, Arat M, Soydan E, Topcuoglu P, Gürman G, Bostancı HS. (2013) Periodontal status and post-transplantation complications following intensive periodontal treatment in patients underwent allogenic hematopoietic stem cell transplantation conditioned with myeloablative. Int J Dent Hyg. 2013 May;11(2):84-90. https://doi.org/10.1111/j.1601-5037.2012.00550.x. Epub 2012 Apr 9.

9. Epstein JB, Güneri P, Barasch A. (2014) Appropriate and necessary oral care for people with cancer: guidance to obtain the right oral and dental care at the right time. Support Care Cancer. 2014 Jul;22(7):1981-8. https://doi.org/10.1007/s00520-014-2228-x. Epub 2014 Mar 28.

10. Elad S, Raber-Durlacher JE, Brennan MT, Saunders DP, Mank AP, Zadik Y, Quinn B, Epstein JB, Blijlevens NM, Waltimo T, Passweg JR, Correa ME, Dahllöf G, Garming-Legert KU, Logan RM, Potting CM, Shapira MY, Soga Y, Stringer J, Stokman MA, Vokurka S, Wallhult E, Yarom N, Jensen SB. (2015) Basic oral care for hematology-oncology patients and hematopoietic stem cell transplantation recipients: a position paper from the joint task force of the Multinational Association of Supportive Care in Cancer/International Society of Oral Oncology (MASCC/ISOO) and the European Society for Blood and Marrow Transplantation (EBMT). Support Care Cancer. 2015 Jan;23(1):223-36. https://doi.org/10.1007/s00520-014-2378-x. Epub 2014 Sep 5.

11. Global Burden of Disease Cancer Collaboration, Fitzmaurice C, Allen C, Barber RM, Barregard L, Bhutta ZA, Brenner H, Dicker DJ, Chimed-Orchir O, Dandona R, Dandona L, Fleming T, Forouzanfar MH, Hancock J, Hay RJ, Hunter-Merrill R, Huynh C, Hosgood HD, Johnson CO, Jonas JB, Khubchandani J, Kumar GA, Kutz M, Lan Q, Larson HJ, Liang X, Lim SS, Lopez AD, Maclntyre MF, Marczak L, Marquez N, Mokdad AH, Pinho C, Pourmalek F, Salomon JA, Sanabria JR, Sandar L, Sartorius B, Schwartz SM, Shackelford KA, Shibuya K, Stanaway J, Steiner C, Sun J, Takahashi K, Vollset SE, Vos T, Wagner JA, Wang H, Westerman R, Zeeb H, Zoeckler L, Abd-Allah F, Ahmed MB, Alabed S, Alam NK, Aldhahri SF, Alem G, Alemayohu MA, Ali R, Al-Raddadi R, Amare A, Amoako Y, Artaman A, Asayesh H, Atnafu N, Awasthi A, Saleem HB, Barac A, Bedi N, Bensenor I, Berhane A, Bernabé E, Betsu B, Binagwaho A, Boneya D, Campos-Nonato I, Castañeda-Orjuela C, Catalá-López F, Chiang P, Chibueze C, Chitheer A, Choi JY, Cowie B, Damtew S, das Neves J, Dey S, Dharmaratne S, 
Dhillon P, Ding E, Driscoll T, Ekwueme D, Endries AY, Farvid M, Farzadfar F, Fernandes J, Fischer F, G/Hiwot TT, Gebru A, Gopalani S, et al. (2016) Global, Regional, and National Cancer Incidence, Mortality, Years of Life Lost, Years Lived With Disability, and Disability-Adjusted Life-years for 32 Cancer Groups, 1990 to 2015: A Systematic Analysis for the Global Burden of Disease Study. JAMA Oncol. 2017 Apr 1;3(4):524-548. https://doi.org/10.1001/jamaoncol.2016.5688.

12. Kressin NR, Manze M, Russell SL, Katz RV, Claudio C, Green BL, Wang MQ. (2010) Self-reported willingness to have cancer screening and the effects of sociodemographic factors. J Natl Med Assoc. 2010 Mar;102(3):219-27. https://doi.org/10.1016/s0027-9684(15)30528-9.

13. Rhodes SD, Bowie DA, Hergenrather KC. (2003) Collecting behavioural data using the world wide web: considerations for researchers. J Epidemiol Community Health. 2003 Jan;57(1):68-73. https://doi.org/10.1136/jech.57.1.68.

14. WHITE PAPER 2017 Information and Communications in Japan. Ministry of Internal Affairs and Communications of Japan.

https://www.soumu.go.jp/johotsusintokei/whitepaper/eng/WP2017/chapter-6.pdf\#page=1 Accessed February 15, 2021.

15. Rakuten Insight Co., Ltd. https://insight.rakuten.co.jp/en/ Accessed July 19, 2020.

16. CANCER STATISTICS IN JAPAN '17. Cancer information service. Center for Cancer Control and Information Services, National Cancer Center. https://ganjoho.jp/en/professional/statistics/brochure/2017_en.html. Accessed March 30, 2021.

17. Takayama T, Yamazaki Y, Katsumata N. (2001) Relationship between outpatients' perceptions of physicians' communication styles and patients' anxiety levels in a Japanese oncology setting. Soc Sci Med. 2001 Nov;53(10):1335-50. https://doi.org/10.1016/s0277-9536(00)00413-5.

18. Tsunematsu M, Kawasaki H, Masuoka Y, Kakehashi M. (2013) Factors affecting breast cancer screening behavior in Japan-assessment using the health belief model and conjoint analysis. Asian Pac J Cancer Prev. 2013;14(10):6041-8. https://doi.org/10.7314/apjcp.2013.14.10.6041.

19. Takahashi O, Ohde S, Jacobs JL, Tokuda Y, Yanai H, Okubo T, Shimbo T, Fukuhara S, Hinohara S, Fukui T. (2010) Population-level preferences for primary care physicians' characteristics in Japan: a structural equation modeling. Intern Med. 2010;49(2):125-30. https://doi.org/10.2169/internalmedicine.49.2572. Epub 2010 Jan 15.

20. Council of Local Authorities for International Relations (2017) Local Government in Japan 2016. Council of Local Authorities for International Relations (CLAIR). http://www.clair.or.jp/j/forum/pub/docs/jichi-en_1.pdf. Accessed 26 Apr 2021

21. Summary of Static/Dynamic Survey of Medical Institutions and Hospital Report, 2014 (2014) Ministry of Health, Labour and Welfare in Japan. https://www.mhlw.go.jp/english/database/dbhss/mih_report_2014.html. Accessed 26 Apr 2021 
22. Lopez-Class M, Luta G, Noone AM, Canar J, Selksy C, Huerta E, Mandelblatt J. (2012) Patient and provider factors associated with colorectal cancer screening in safety net clinics serving low-income, urban immigrant Latinos J Health Care Poor Underserved. 2012 Aug;23(3):1011-9. https://doi.org/10.1353/hpu.2012.0109.

23. Tinoco-Araujo JE, Orti-Raduan ES, Santos D, Colturato VA, Souza MP, Mauad MA, Saggioro TC, Bastos RS, da Silva Santos PS. (2015) Oral health-related quality of life before hematopoietic stem cell transplantation. Clin Oral Investig. 2015 Dec;19(9):2345-9. https://doi.org/10.1007/s00784-0151464-x. Epub 2015 Apr 1.

24. West CP, Dyrbye LN, Erwin PJ, Shanafelt TD. (2016) Interventions to prevent and reduce physician burnout: a systematic review and meta-analysis. Lancet. 2016 Nov 5;388(10057):2272-2281. https://doi.org/10.1016/S0140-6736(16)31279-X. Epub 2016 Sep 28.

25. Salem R, Akel R, Fakhri G, Tfayli A. (2018) Burnout among Lebanese Oncologists: Prevalence and Risk Factors. Asian Pac J Cancer Prev. 2018 Aug 24;19(8):2135-2139. https://doi.org/10.22034/APJCP.2018.19.8.2135.

26. Murali K, Banerjee S. (2018) Burnout in oncologists is a serious issue: What can we do about it? Cancer Treat Rev. 2018 Jul;68:55-61. https://doi.org/10.1016/j.ctrv.2018.05.009. Epub 2018 May 16.

27. McGuire DB. (2003) Barriers and strategies in implementation of oral care standards for cancer patients. Support Care Cancer. 2003 Jul;11(7):435-41. https://doi.org/10.1007/s00520-003-0466-4. Epub 2003 Apr 12.

28. Ruberton PM, Huynh HP, Miller TA, Kruse E, Chancellor J, Lyubomirsky S. (2016) The relationship between physician humility, physician-patient communication, and patient health. Patient Educ Couns. 2016 Jul;99(7):1138-1145. https://doi.org/10.1016/j.pec.2016.01.012. Epub 2016 Jan 21.

29. Hiramatsu T, Sugiyama M, Kuwabara S, Tachimori Y, Nishioka M. (2014) Effectiveness of an outpatient preoperative care bundle in preventing postoperative pneumonia among esophageal cancer patients. Am J Infect Control. 2014 Apr;42(4):385-8. https://doi.org/10.1016/j.ajic.2013.11.017.

30. Iwata E, Hasegawa T, Yamada SI, Kawashita Y, Yoshimatsu M, Mizutani T, Nakahara H, Mori K, Shibuya Y, Kurita H, Komori T. (2019) Effects of perioperative oral care on prevention of postoperative pneumonia after lung resection: Multicenter retrospective study with propensity score matching analysis. Surgery. 2019 May;165(5):1003-1007. https://doi.org/10.1016/j.surg.2018.11.020. Epub 2019 Feb 11.

31. Soutome S, Yanamoto S, Funahara M, Hasegawa T, Komori T, Yamada SI, Kurita H, Yamauchi C, Shibuya Y, Kojima Y, Nakahara H, Oho T, Umeda M. (2017) Effect of perioperative oral care on prevention of postoperative pneumonia associated with esophageal cancer surgery: A multicenter case-control study with propensity score matching analysis. Medicine (Baltimore). 2017 Aug;96(33):e7436. https://doi.org/10.1097/MD.0000000000007436.

32. Nobuhara $H$, Yanamoto $S$, Funahara M, Matsugu $Y$, Hayashida S, Soutome S, Kawakita A, Ikeda S, Itamoto T, Umeda M. (2018) Effect of perioperative oral management on the prevention of surgical 
site infection after colorectal cancer surgery: A multicenter retrospective analysis of 698 patients via analysis of covariance using. Medicine (Baltimore). 2018 Oct;97(40):e12545. https://doi.org/10.1097/MD.0000000000012545.

\section{Supplementary Files}

This is a list of supplementary files associated with this preprint. Click to download.

- ESM1.pdf 